\title{
Comparison of Chief Complaints and Patient-Reported Symptoms of Treatment-Naive Lung Cancer Patients Before Surgery
}

\author{
Yaqian Feng (iD) \\ Wei Dai' \\ Yaqin Wang ${ }^{\prime}$ \\ Jia Liao' \\ Xing Wei ${ }^{1}$ \\ Shaohua Xie' \\ Wei $X u^{2}$ \\ Qiang $\mathrm{Li}^{1}$ \\ Fang Liu $^{3}$ \\ Qiuling Shi ${ }^{4}$ \\ 'Department of Thoracic Surgery, Sichuan \\ Cancer Hospital \& Institute, School of \\ Medicine, University of Electronic Science \\ and Technology of China, Chengdu, \\ 61004I, People's Republic of China; \\ ${ }^{2}$ School of Public Health and Management, \\ Chongqing Medical University, Chongqing, \\ People's Republic of China; ${ }^{3}$ Traditional \\ Chinese Medicine Department of \\ Oncology, Sichuan Cancer Hospital \& \\ Institute, School of Medicine, University of \\ Electronic Science and Technology of \\ China, Chengdu, 61004I, People's Republic \\ of China; ${ }^{4}$ Center for Cancer Prevention \\ Research, Sichuan Cancer Hospital \& \\ Institute, School of Medicine, University of \\ Electronic Science and Technology of \\ China, Chengdu, 6I004I, People's Republic \\ of China
}

Correspondence: Qiuling Shi; Fang Liu Sichuan Cancer Hospital \& Institute, Sichuan Cancer Center, School of Medicine, University of Electronic Science and Technology of China, No. 55, Section 4, South Renmin Road, Chengdu, 61004I, People's Republic of China Email qshi@cqmu.edu.cn; 1937239721@qq.com
Background: Lung cancer patients without chief complaints have been increasingly identified by physical examination. This study aimed to profile and compare chief complaints with patient-reported symptoms of lung cancer patients before surgery.

Methods: Data were extracted from a multicenter, prospective longitudinal study (CN-PROLung 1) in China from November 2017 to January 2020. A comparison between chief complaints and patient-reported symptoms was analyzed using the Chi-squared test.

Results: A total of 201 (50.8\%) lung cancer patients without chief complaints were found by physical examination at admission, and 195 (49.2\%) patients had chief complaints. The top 5 chief complaints were coughing (38.1\%), expectoration (25.5\%), chest pain (13.6\%), hemoptysis $(10.6 \%)$, and shortness of breath $(5.3 \%)$. There were significantly more patients with chief complaints of coughing $(38.1 \%$ vs $15.0 \%, \mathrm{P}<0.001)$ and pain $(20.5 \%$ vs $6.9 \%$, $\mathrm{P}<0.001)$ than those with the same symptoms rated $\geq 4$ via MD Anderson Symptom Inventory-Lung Cancer (MDASI-LC). There were less patients with chief complaints of fatigue $(1.8 \%$ vs $10.9 \%, \mathrm{P}<0.001)$, nausea $(0.3 \%$ vs $2.5 \%, \mathrm{P}=0.006)$, and vomiting $(0.3 \%$ vs $1.8 \%, \mathrm{p}=0.032$ ) than those with the same symptoms rated $\geq 4$ via MDASI-LC. In patients without chief complaints, the five most common moderate to severe patient-reported symptoms were disturbed sleep (19.5\%), distress (13.5\%), dry mouth (13\%), sadness $(12 \%)$, and difficulty remembering (11.1\%).

Conclusion: Symptoms of lung cancer patients not included in the chief complaint could be identified via a patient-reported outcome instrument, suggesting the necessity of implementing the patient-reported outcome assessment before lung cancer surgery for better patient care.

Keywords: lung cancer, chief complaint, surgery, symptom, patient-reported outcomes

\section{Introduction}

Lung cancer is one of the most common cancers worldwide. ${ }^{1}$ Coughing, hemoptysis, and chest pain were initially known as the principal signs of lung cancer. ${ }^{2}$ In recent years, however, with low-dose computerized tomography (CT) being applied in physical examination, ${ }^{3,4}$ more lung cancer patients without chief complaints are being diagnosed by physical examinations rather than by specific symptoms.

Chief complaints may not reflect some potential symptoms that might be identified by patient-reported outcome (PRO) measures. ${ }^{5}$ PRO refers to any report that comes directly from the patient about their own health rather than from the clinician or someone else. ${ }^{6}$ Research in this area has shown that PRO can identify 
symptoms that clinicians may overlook. ${ }^{7}$ Most previous articles related to lung cancer focused on postoperative patients or patients undergoing non-surgical treatment. ${ }^{8,9}$ Few studies investigated preoperative patients with lung cancer and how preoperative chief complaints might be concordant with PROs is still unknown. Therefore, as lung cancer patients are increasingly identified by physical examination, it is necessary to identify patients' potential symptoms before surgery in order to provide early clinical intervention. $^{10,11}$ The goal of this study was to identify and compare chief complaints and patient-reported symptoms of treatment-naive patients before lung cancer surgery.

\section{Materials and Methods}

\section{Patient Selection}

Data for this cross-sectional design study were extracted from a multicenter, prospective longitudinal study $(\mathrm{CN}-$ PRO-Lung 1) in China from November 2017 and January 2020. The inclusion criteria of patients were: aged $\geq 18$ years, had not received any cancer therapy, did not have other cancer histories, pathologically diagnosed as lung cancer, and received surgical treatment. Most of the patients received the histological diagnosis after surgery.

\section{Data Collection}

The electronic medical record system provided demographic, surgical and pathological data. In this analysis, the body mass index (BMI) of Chinese adults was reclassified based on heterogeneity in the Chinese population. Individuals with BMI $<18.5 \mathrm{~kg} / \mathrm{m}^{2}$ were classified as low weight, $18.5-23.9 \mathrm{~kg} / \mathrm{m}^{2}$ as average weight, $24.0-27.9 \mathrm{~kg} / \mathrm{m}^{2}$ as overweight, and $\geq 28.0 \mathrm{~kg} / \mathrm{m}^{2}$ as obese. ${ }^{12}$

The symptoms reported by patients were derived from the definition of the MD Anderson Symptom Inventory Lung Cancer Module (MDASI-LC), a validated PRO system designed to assess the severity of multiple symptoms experienced by lung cancer patients. ${ }^{9}{ }^{13-15}$ MDASI-LC includes 16 treatment-related core symptoms and 6 daily functional impairment caused by symptoms, with a recall period of 24 hours. The severity score for each symptom ranges from 0 to 10 points with 0 being asymptomatic, 1-3 being mild symptoms, 4-6 being moderate symptoms, 7 or greater being severe symptoms, and 10 being extreme symptoms. ${ }^{16}$ MDASI-LC has been recognized an effective and essential tool for quantifying the overall symptom burden for patients with lung cancer. ${ }^{17}$ All the patients filled out the MDASI-LC questionnaire before surgery.

Research Electronic Data Capture (REDCap) is adopted for data management, and all data are finally entered into the project database of this system. The REDCap system was introduced to our hospital by the end of 2017 and hosted at the server of Sichuan Cancer Hospital. $^{18,19}$

\section{Statistical Analysis}

All analyses were performed using SPSS V23.0 software. Symptom items with missing were excluded from the analysis for the corresponding patient. Demographic data, clinical data, and PROs were presented as numbers and percentages and compared using the Chi-squared test. A two-sided $\mathrm{P}$ value less than 0.05 was considered statistically significant.

\section{Results \\ Basic Clinical Data}

This study involved a total of 396 patients, comprising 209 $(52.8 \%)$ male and $187(47.2 \%)$ female. Over $60 \%$ of the patients were aged $\leq 60$ years $(65.2 \%)$ and $62.1 \%$ had no history of smoking. The majority had adenocarcinoma $(82.1 \%)$ and early-stage disease $(64.6 \%){ }^{20}$ The American Society of Anesthesiologists classification of most patients was $0-1(97.2 \%)$. Most patients had a BMI between 18.5 and $23.9(60.9 \%)$ and $70.5 \%$ presented Charlson Comorbidity Index more than 1 (Table 1).

\section{Chief Complaints}

Out of the 396 patients, 201 patients found by physical examination were without chief complaints at admission. In the group of patients without chief complaints, many patients had lung masses found on annual physical examination by chest $\mathrm{CT}$ scan. Some lung cancers were detected due to additional check-up for other diseases, and a few were detected due to CT screening programme. And 195 patients had chief complaints. The top 5 chief complaints were coughing $(38.1 \%)$, expectoration $(25.5 \%)$, chest pain $(13.6 \%)$, hemoptysis (10.6\%) and shortness of breath (5.3\%) (Table 2).

\section{Comparison of Same Chief Complaints and Patient-Reported Symptoms}

The chief complaints were compared with the same symptoms assessed by MDASI-LC. There were significantly 
Table I Demographic and Basic Clinical Characteristics of the 396 Patients

\begin{tabular}{|c|c|}
\hline Variables & Number (\%) \\
\hline \multicolumn{2}{|l|}{ Age (years) } \\
\hline$\leq 60$ & $258(65.2)$ \\
\hline$>60$ & $138(34.8)$ \\
\hline \multicolumn{2}{|l|}{ Gender } \\
\hline Male & $209(52.8)$ \\
\hline Female & $187(47.2)$ \\
\hline \multicolumn{2}{|l|}{ Chief complaint } \\
\hline No & $20 \mathrm{I}(50.8)$ \\
\hline Yes & $195(49.2)$ \\
\hline \multicolumn{2}{|l|}{ Smoking history } \\
\hline No & $246(62.1)$ \\
\hline Yes & 150 (37.9) \\
\hline \multicolumn{2}{|l|}{ Pathological type } \\
\hline Adenocarcinoma & $325(82.1)$ \\
\hline Non-adenocarcinoma & 71 (I7.9) \\
\hline \multicolumn{2}{|l|}{ Pathological tumor stage } \\
\hline $0-1$ & $256(64.6)$ \\
\hline II-IV & 140 (35.4) \\
\hline \multicolumn{2}{|l|}{ ASA classification } \\
\hline $0-1$ & $385(97.2)$ \\
\hline II-IV & II (2.8) \\
\hline \multicolumn{2}{|l|}{ Body Mass Index $\left(\mathrm{kg} / \mathrm{m}^{2}\right)$} \\
\hline$<18.5$ & $18(4.5)$ \\
\hline $18.5-23.9$ & $24 I(60.9)$ \\
\hline$\geq 24.0$ & $137(34.6)$ \\
\hline \multicolumn{2}{|l|}{ Charlson Comorbidity Index } \\
\hline 0 & $117(29.5)$ \\
\hline $\mathrm{I}-5$ & $279(70.5)$ \\
\hline
\end{tabular}

Abbreviation: ASA, American Society of Anesthesiologists.

more patients with chief complaints of coughing (38.1\% vs $14.9 \%, \mathrm{P}<0.001)$ and pain $(20.5 \%$ vs $6.8 \%, \mathrm{P}<0.001)$ than those with the same symptoms rated $\geq 4$ via MDASILC. There were less patients with chief complaints of fatigue $(1.8 \%$ vs $10.9 \%, \mathrm{P}<0.001)$, nausea $(0.3 \%$ vs $2.5 \%, \mathrm{P}=0.006)$, and vomiting $(0.3 \%$ vs $1.8 \%, \mathrm{P}=0.032)$ than those with same symptoms rated $\geq 4$ via MDASI-LC (Table 3).

\section{Patient-Reported Symptoms in Patients without Chief Complaints}

In patients without chief complaints, the most prevalent (MDASI-LC item rated $\geq 1$ ) patient-reported symptoms
Table 2 The Chief Complaints of the 396 Patients

\begin{tabular}{|l|l|}
\hline Symptoms & Number (\%) \\
\hline Incidental finding and asymptomatic & $20 \mathrm{I}(50.8)$ \\
Coughing & $\mathrm{I} 5 \mathrm{I}(38 . \mathrm{I})$ \\
Expectoration & $\mathrm{I} 0 \mathrm{I}(25.5)$ \\
Chest pain & $54(13.6)$ \\
Hemoptysis & $42(10.6)$ \\
Shortness of breath & $2 \mathrm{I}(5.3)$ \\
Chest distress & $\mathrm{I} 5(3.8)$ \\
Back pain & $14(3.5)$ \\
Other symptoms & $13(3.3)$ \\
Fever & $8(2.0)$ \\
Fatigue & $7(1.8)$ \\
Headache & $6(1.5)$ \\
Weight loss & $5(1.3)$ \\
Shoulder pain & $4(1.0)$ \\
Hoarseness & $3(0.8)$ \\
Other signs & $3(0.8)$ \\
Abdominal pain & $2(0.5)$ \\
Nausea & $\mathrm{I}(0.3)$ \\
Vomiting & $\mathrm{I}(0.3)$ \\
Palpitation & $\mathrm{I}(0.3)$ \\
\hline
\end{tabular}

Table 3 Comparison of Same Chief Complaints and PatientReported Symptoms

\begin{tabular}{|l|c|c|c|}
\hline Symptom & $\begin{array}{c}\text { Chief } \\
\text { Complaint, } \\
\text { n (\%) }\end{array}$ & $\begin{array}{c}\text { MDASI-LC } \\
\text { Item Rated } \\
\geq \mathbf{4}, \mathbf{n} \text { (\%) }\end{array}$ & P value \\
\hline Coughing & $15 \mathrm{I}(38.1)$ & $59(14.9)$ & $<0.00 \mathrm{I}$ \\
Pain & $8 \mathrm{I}(20.5)$ & $27(6.8)$ & $<0.00 \mathrm{I}$ \\
Shortness of breath & $2 \mathrm{I}(5.3)$ & $3 \mathrm{I}(7.8)$ & 0.146 \\
Fatigue & $7(\mathrm{I} .8)$ & $43(10.9)$ & $<0.00 \mathrm{I}$ \\
Nausea & $\mathrm{I}(0.3)$ & $10(2.5)$ & 0.006 \\
Vomiting & $\mathrm{I}(0.3)$ & $7(1.8)$ & 0.032 \\
\hline
\end{tabular}

were disturbed sleep (49\%), dry mouth (49\%), difficulty remembering $(46.2 \%)$, coughing $(46 \%)$, and fatigue (36\%). The most common moderate to severe patientreported (MDASI-LC item rated $\geq 4$ ) symptoms were disturbed sleep (19.5\%), distress (13.5\%), dry mouth (13\%), sadness (12\%), and difficulty remembering (11.1\%) (Table 4).

\section{Discussion}

In this study, we found that symptom patterns from chief complaints were different from patient-reported symptoms. This study showed that currently the majority of lung cancer patients had no chief complaints before surgery. However, symptoms not included in the chief 
Table 4 Patient-Reported Symptoms in Patients without Chief Complaints

\begin{tabular}{|l|c|c|c|}
\hline Symptoms & $\begin{array}{c}\text { Available } \\
\text { Cases (N) }\end{array}$ & $\begin{array}{c}\text { MDASI- } \\
\text { LC Item } \\
\text { Rated } \\
\geq \mathbf{I}, \mathbf{n} \text { (\%) }\end{array}$ & $\begin{array}{c}\text { MDASI- } \\
\text { LC Item } \\
\text { Rated } \\
\geq \mathbf{4 , ~ n ~ ( \% ) ~}\end{array}$ \\
\hline Disturbed sleep & 200 & $98(49)$ & $39(19.5)$ \\
Dry mouth & 200 & $98(49)$ & $26(13)$ \\
Difficulty remembering & 199 & $92(46.2)$ & $22(I I .1)$ \\
Coughing & 200 & $92(46)$ & $13(6.5)$ \\
Fatigue & 200 & $72(36)$ & $17(8.5)$ \\
Drowsiness & $20 \mathrm{I}$ & $72(35.8)$ & $1 \mathrm{I}(5.5)$ \\
Distress & 200 & $66(33)$ & $27(13.5)$ \\
Sadness & 200 & $60(30)$ & $24(12)$ \\
Constipation & 200 & $59(29.5)$ & $19(9.5)$ \\
Lack of appetite & $20 \mathrm{I}$ & $59(29.4)$ & $8(4.0)$ \\
Shortness of breath & $20 \mathrm{I}$ & $58(28.9)$ & $9(4.5)$ \\
Sore throat & 200 & $57(28.5)$ & $7(3.5)$ \\
Numbness or tingling & $20 \mathrm{I}$ & $37(18.4)$ & $4(2.0)$ \\
Pain & 200 & $34(17)$ & $8(4)$ \\
Nausea & 199 & $23(1 \mathrm{I}) 6)$ & $5(2.5)$ \\
Vomiting & $20 \mathrm{I}$ & $19(9.5)$ & $6(3.0)$ \\
\hline
\end{tabular}

complaints have been identified via a PRO instrument, suggesting the need to implement the PRO assessment before lung cancer surgery for better patient care.

A study by Birring et al showed that coughing, hemoptysis, and chest pain were the most common complaints of lung cancer patients. ${ }^{2}$ However, the most common complaints of subjects revealed in our study were coughing, expectoration, and chest pain. The likely reason for this inconsistency is that Birring's analysis targeted lung cancer patients with all stages of disease whereas our patients were mostly in the early lung cancer stages.

Our results, in accordance with other recent studies, ${ }^{10,21}$ suggested that PRO may be an essential supplement to evaluate symptoms from traditional standard chief complaints. It is generally believed that patients with symptoms reported $\geq 4$ is thought to be reflected in the chief complaint, such as fatigue, nausea, and vomiting, but coughing and pain are not. Our research showed there were significantly more patients with chief complaints of coughing and pain than those with the same symptoms rated $\geq 4$ via MDASI-LC. The possible explanation is that the intense discomfort caused by coughing and pain is more likely to affect a patient's daily life, and thus more easily attract attention. The systemic symptoms of fatigue, nausea, and vomiting attract less attention and so are less likely to be reflected through the chief complaint, indicating that some general symptoms will not be contemplated by the chief complaint but need to be reflected by the PRO. Therefore, future clinical work probably needs to focus more on the patient's psychological state.

Previous studies have proven the importance of identifying initial signs for early diagnosis of lung cancer. ${ }^{22}$ Lung cancer patients often have respiratory symptoms at the onset of lung cancer, the most common being coughing, hemoptysis and chest pain. But now more lung cancer patients are found by physical examination. The most common symptoms noticed after physical examinations are disturbed sleep, dry mouth, difficulty remembering, sadness, and fatigue. A study by Mendoza et al revealed that a large proportion of patients with lung cancer are symptomatic. ${ }^{23}$ Precise awareness of the primary burden of symptoms is not only useful in evaluating patient-specific therapies but is also crucial in separating disease-related symptoms from potential future treatment-related symptoms. PRO can detect some underlying symptoms. The patient's chief complaint does not include any psychological symptoms, and if the doctor does not ask, the patients will not complain. PRO assessment does not involve a doctor and is more comprehensive than chief complaint assessment. ${ }^{24}$ Some potential symptoms (mostly non-specific or psychological symptoms) are difficult to identify during the chief complaint of patients. Through our research, we can more accurately and comprehensively evaluate the symptoms of patients, especially psychological problems. In this study, the most common moderate-to-severe patient-reported symptoms before surgery were disturbed sleep, distress, dry mouth, sadness, and difficulty remembering. Clinically, the above symptoms without chief complaint are not evaluated or treated, while according to the National Comprehensive Cancer Network guidelines, the most common moderate-to-severe patientreported symptoms of distress need to be addressed. ${ }^{25}$ All of these symptoms may affect the patient's postoperative recovery and quality of life. When patients report their symptoms, problems, and concerns and nurses and physicians received the resulting assessment summaries, the clinicians addressed significantly more symptoms and problems in patients' reflection. Patients also reported less symptom distress and need for symptom management support over time during treatment and rehabilitation. ${ }^{26}$ An PRO system with the functionality to apply clinical algorithms to automatically alert clinicians in real-time of atypical symptoms has the potential to improve symptom control, patient safety 
and outcomes and decrease emergency admissions, with the additional potential of healthcare cost savings. ${ }^{27}$ And the use of PRO in clinical practice seems to be most effective in increasing patient satisfaction with communication about emotional concerns. $^{28}$

This study has several limitations. Firstly, MDASI-LC is a specific scale for lung cancer, but it was developed and verified in lung cancer patients with chemoradiotherapy, and its symptom items may not completely represent the symptoms of patients undergoing surgery. However, no surgery-specific scale is currently available for lung cancer. Secondly, although the population in this study was large, all patients were from Sichuan Province, thus limiting the ability to generalize findings to all of China. However, our lung cancer data were basically consistent with the global data, ${ }^{29}$ so our study findings may also apply at the global level.

\section{Conclusions}

Our study highlights the importance of PRO for the management of lung cancer. Currently, the chief complaints of lung cancer patients have gradually changed. These findings suggest that implementing the PRO assessment before lung cancer surgery is necessary for better patient care.

\section{Abbreviations}

CT, computerized tomography; BMI, body mass index; PRO, patient-reported outcome; MDASI-LC, MD Anderson Symptom Inventory Lung Cancer Module; RED Cap, Research Electronic Data Capture.

\section{Ethics Approval and Consent to Participate}

The study protocol was approved by the Ethics Committee of Sichuan Cancer Hospital (approved number: SCCHEC02-2017-042).

I confirm that all experiments were performed in accordance with relevant guidelines and regulations, and confirm that informed consent was obtained from all subjects. This study was conducted in accordance with the Declaration of Helsinki. We are willing to share data related to this article with other researchers. Other researchers can contact the corresponding author by email. We will provide relevant data for this study.

\section{Acknowledgments}

We thank the patients for their cooperation and time. The abstract was selected for presentation as poster in $23 \mathrm{rd}$ Chinese Society of Clinical Oncology.

\section{Funding}

This work was supported by grants from the Sichuan Science and Technology Program (No. 2019YFH0070) and National Natural Science Foundation of China (No. 81872506).

\section{Disclosure}

The authors declare that there are no conflicts of interest regarding the publication of this paper.

\section{References}

1. Siegel RL, Miller KD, Jemal A. Cancer statistics, 2020. CA Cancer J Clin. 2020;70(1):7-30. doi:10.3322/caac.21590

2. Birring SS, Peake MD. Symptoms and the early diagnosis of lung cancer. Thorax. 2005;60(4):268-269. doi:10.1136/thx.2004.032698

3. Lopes Pegna A, Picozzi G, Falaschi F, et al. Four-year results of low-dose CT screening and nodule management in the ITALUNG trial. $J$ Thorac Oncol. 2013;8(7):866-875. doi:10.1097/ JTO.0b013e31828f68d6

4. Khullar OV, Rajaei MH, Force SD, et al. Pilot study to integrate patient reported outcomes after lung cancer operations into the Society of Thoracic Surgeons Database. Ann Thorac Surg. 2017;104(1):245-253. doi:10.1016/j.athoracsur.2017.01.110

5. Hjollund NHI. Individual prognosis of symptom burden and functioning in chronic diseases: a generic method based on patient-reported outcome (PRO) measures. J Med Internet Res. 2017;19(8):e278. doi:10.2196/jmir.8111

6. U.S. Department of Health and Human Services FDA Center for Drug Evaluation and Research; U.S. Department of Health and Human Services FDA Center for Biologics Evaluation and Research; U.S. Department of Health and Human Services FDA Center for Devices and Radiological Health. Guidance for industry: patient-reported outcome measures: use in medical product development to support labeling claims: draft guidance. Health Qual Life Outcomes. 2006;4:79.

7. Basch E. Missing patients' symptoms in cancer care delivery-the importance of patient-reported outcomes. JAMA Oncol. 2016;2 (4):433-434. doi:10.1001/jamaoncol.2015.4719

8. Cleeland CS, Wang XS, Shi Q, et al. Automated symptom alerts reduce postoperative symptom severity after cancer surgery: a randomized controlled clinical trial. J Clin Oncol. 2011;29 (8):994-1000. doi:10.1200/JCO.2010.29.8315

9. Basch E, Deal AM, Dueck AC, et al. Overall survival results of a trial assessing patient-reported outcomes for symptom monitoring during routine cancer treatment. JAMA. 2017;318(2):197-198. doi:10.1001/ jama.2017.7156

10. Basch E, Jia X, Heller G, et al. Adverse symptom event reporting by patients vs clinicians: relationships with clinical outcomes. $J$ Natl Cancer Inst. 2009;101(23):1624-1632. doi:10.1093/jnci/djp386

11. Dai W, Xie S, Zhang R, et al. Developing and validating utility parameters to establish patient-reported outcome-based perioperative symptom management in patients with lung cancer: a multicentre, prospective, observational cohort study protocol. BMJ Open. 2019;9 (10):e030726. doi:10.1136/bmjopen-2019-030726 
12. Zhou B. Coorperative Meta-Analysis Group of China Obesity Task Force. Zhonghua Liu Xing Bing Xue Za Zhi. 2002;23(1):5-10.

13. Jensen RE, Rothrock NE, DeWitt EM, et al. The role of technical advances in the adoption and integration of patient-reported outcomes in clinical care. Med Care. 2015;53(2):153-159. doi:10.1097/ MLR.0000000000000289

14. Yun YH, Kim YA, Sim JA, et al. Prognostic value of quality of life score in disease-free survivors of surgically-treated lung cancer. $B M C$ Cancer. 2016;16:505. doi:10.1186/s12885-016-2504-X

15. Cleeland CS, Mendoza TR, Wang XS, et al. Assessing symptom distress in cancer patients: the M.D. Anderson Symptom Inventory. Cancer. 2000;89(7):1634-1646. doi:10.1002/1097-0142(20001001) 89:7<1634::AID-CNCR29>3.0.CO;2-V

16. Fagundes CP, Shi Q, Vaporciyan AA, et al. Symptom recovery after thoracic surgery: measuring patient-reported outcomes with the MD Anderson Symptom Inventory. J Thorac Cardiovasc Surg. 2015;150 (3):613-9.e2. doi:10.1016/j.jtcvs.2015.05.057

17. Mendoza TR, Wang XS, Lu C, et al. Measuring the symptom burden of lung cancer: the validity and utility of the lung cancer module of the M. D. Anderson Symptom Inventory. Oncologist. 2011;16 (2):217-227. doi:10.1634/theoncologist.2010-0193

18. Harris PA, Taylor R, Minor BL, et al. The REDCap consortium: building an international community of software platform partners. J Biomed Inform. 2019;95:103208. doi:10.1016/j.jbi.2019.103208

19. Harris PA, Taylor R, Thielke R, Payne J, Gonzalez N, Conde JG. Research electronic data capture (REDCap)-a metadata-driven methodology and workflow process for providing translational research informatics support. $J$ Biomed Inform. 2009;42(2):377-381. doi:10.1016/j.jbi.2008.08.010

20. Bade BC, Dela Cruz CS. Lung cancer 2020: epidemiology, etiology, and prevention. Clin Chest Med. 2020;41(1):1-24. doi:10.1016/j. ccm.2019.10.001

21. Basch E. The missing voice of patients in drug-safety reporting. $N$ Engl J Med. 2010;362(10):865-869. doi:10.1056/NEJMp0911494

22. Spiro SG, Gould MK, Colice GL; American College of Chest Physicians. Initial evaluation of the patient with lung cancer: symptoms, signs, laboratory tests, and paraneoplastic syndromes: ACCP evidenced-based clinical practice guidelines (2nd edition). Chest. 2007;132(3Suppl):149S-160S. doi:10.1378/chest.07-1358
23. Mendoza TR, Kehl KL, Bamidele O, et al. Assessment of baseline symptom burden in treatment-naïve patients with lung cancer: an observational study. Support Care Cancer. 2019;27(9):3439-3447. doi:10.1007/s00520-018-4632-0

24. Castellano D, Del Muro XG, Pérez-Gracia JL, et al. Patient-reported outcomes in a Phase III, randomized study of sunitinib versus interferon-\{alpha\} as first-line systemic therapy for patients with metastatic renal cell carcinoma in a European population. Ann Oncol. 2009;20(11):1803-1812. doi:10.1093/annonc/mdp067

25. Riba MB, Donovan KA, Andersen B, et al. Distress management, Version 3.2019, NCCN Clinical Practice Guidelines in Oncology. J Natl Compr Canc Netw. 2019;17(10):1229-1249. doi:10.6004/jnccn.2019.0048

26. Ruland CM, Holte HH, Røislien J, et al. Effects of a computersupported interactive tailored patient assessment tool on patient care, symptom distress, and patients' need for symptom management support: a randomized clinical trial. J Am Med Inform Assoc. 2010;17 (4):403-410. doi:10.1136/jamia.2010.005660

27. Avery KNL, Richards HS, Portal A, et al. Developing a real-time electronic symptom monitoring system for patients after discharge following cancer-related surgery. BMC Cancer. 2019;19(1):463. doi:10.1186/s12885-019-5657-6

28. Kotronoulas G, Kearney N, Maguire R, et al. What is the value of the routine use of patient-reported outcome measures toward improvement of patient outcomes, processes of care, and health service outcomes in cancer care? A systematic review of controlled trials. J Clin Oncol. 2014;32(14):1480-1501. doi:10.1200/JCO.2013.53.5948

29. Ettinger DS, Wood DE, Aggarwal C, et al. NCCN guidelines insights: non-small cell lung cancer, Version 1.2020. J Natl Compr Canc Netw. 2019;17(12):1464-1472. doi:10.6004/jnccn.2019.0059
Patient Preference and Adherence

\section{Publish your work in this journal}

Patient Preference and Adherence is an international, peer-reviewed, open access journal that focusing on the growing importance of patient preference and adherence throughout the therapeutic continuum. Patient satisfaction, acceptability, quality of life, compliance, persistence and their role in developing new therapeutic modalities and compounds to optimize clinical outcomes for existing disease states are major areas of interest for the journal. This journal has been accepted for indexing on PubMed Central. The manuscript management system is completely online and includes a very quick and fair peer-review system, which is all easy to use. Visit http:// www.dovepress.com/testimonials.php to read real quotes from published authors. 